\title{
Capable of Gas Sensor MQ-135 to Monitor the Air Quality with Arduino uno
}

\author{
Farah Neamah Abbas \\ Department of Computer Science \\ College of Education \\ Mustansiriyah University, Baghdad, Iraq
}

ORCID: 0000-0001-8603-6650

\author{
Zainab Khyioon Abdalrdha \\ Department of Computer Science, \\ College of Education \\ Mustansiriyah University, Baghdad, Iraq.
}

ORCID: 0000-0002-4440-6040

\author{
Mis.Intisar Mohsin Saadoon \\ Department of Computer Science \\ College of Education \\ Mustansiriyah University, Baghdad, Iraq
}

ORCID: 0000-0002-1292-5364

\author{
Elaf Nassir Abud \\ Department of Computer Science, \\ College of Education, Mustansiriyah University, Baghdad, Iraq.
}

\begin{abstract}
Air pollutants mainly comprises of harmful gases. MQ-135 is a $\mathrm{SnO} 2$ semiconductor based gas sensor capable of MQ-135 such as $\mathrm{CO}, \mathrm{CO} 2$, Ethanol, NH4, Toluene and Acetone in the ambient air [1]. Air pollution is increasing due to the number and monitoring of human activities, which are vital to the relaxation of some measures to control it. We have used a low cost and low power sensor to monitor the air quality.
\end{abstract}

Keywords: Arduino UNO, Shield SIM 900 , Air Quality Monitor(AQM), Gas sensor MQ-135, Part Per Melon (PPM).

\section{Introduction}

MQ-135 gas sensor provide the system with data which is calculated to find the concentration of gases like $\mathrm{CO}, \mathrm{CO} 2$, NH4, Acetone, Toulene and Ethanol[2]. Accounts are completed using Arduino program [3,4]. The final output is send massage to admin via SIM 900 and used LED \& Buzzer alarm in case there is pollutant in the indoor environment as show in Block diagram figure 1.

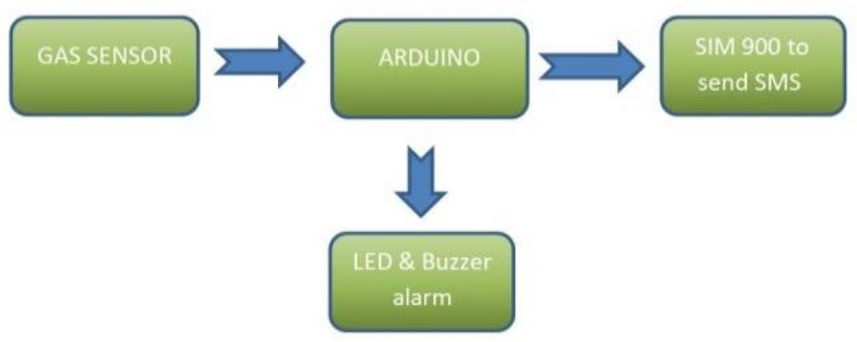

Figure 1: Block diagram

The main objective of this project was Air Quality
Monitor(AQM) using a microcontroller, which includes gas sensor MQ-135 for gases CO, CO2, NH4, Ethanol, Acetone, Toluene. We have measure the concentration of gases then the data send massage to admin via SIM 900 and used LED \& Buzzer alarm in case there are pollutant in the indoor environment.

\section{Requirement Hardware}

1. Arduino UNO x1.

2. SIM900 GSM GPRS Shield x1.

3. MQ-135 - Gas Sensor x1.

4. Buzzer 5volte x1.

5. LEDs $x 4$.

6. Battery lithium 3.7 v $750 \mathrm{mAh} x 4$.

7. Wire Jumpers.

8. NO\OFF bottom $\mathrm{x} 1$.

9. Charging port $\mathrm{x} 1$.

10. Diode $\mathrm{x} 1$.

\section{Gas_sensor_MQ}

The (MQ-X) gas_sensors figure 2 are utilized sensor module comes with a Digital Pin which makes this sensor to operate even without a microcontroller and that comes in handy when only trying to detect one particular gas[5].

To measure the gases in PPM (part per melon) the analog pin need to be used. The analog TTL is operated and operates at 5 volts, thus it can be used with most common microcontrollers. In our project, we will use the (MQ_135) gas sensor[6]. 


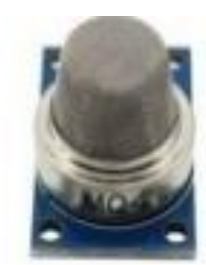

MQ-2
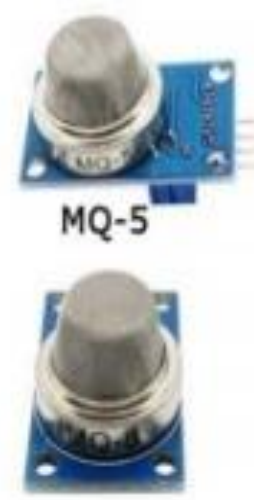

MQ-8

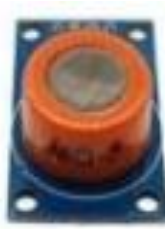

MQ-3

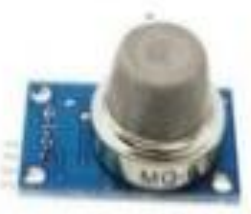

MQ-6

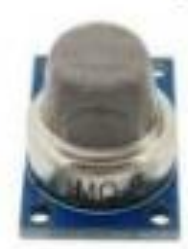

MQ-9

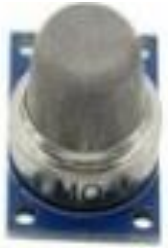

MQ-4

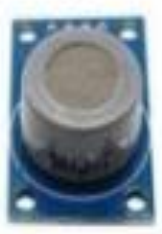

MQ-7

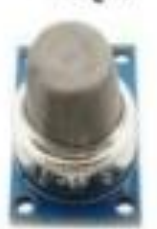

MQ-135
Figure 2: MQ-X Gas sensors

\section{Gas_sensor MQ}

The (MQ-135) gas sensor figure 3 utilized for air quality and are detecting or measuring of $\mathrm{NOx}, \mathrm{Nh} 3, \mathrm{CO} 2$, Benzene, Alcohol ,Smoke. The (MQ-135) sensar comes with a digital pin that makes this sensor work with or without micro_controller, which is good use when trying to discover one particular gas. To measure the gases in PPM (part per melon) the analog pin need to be used. The analog TTL is operated and operates at 5 volts and so can be used with most common microcontrollers[7].

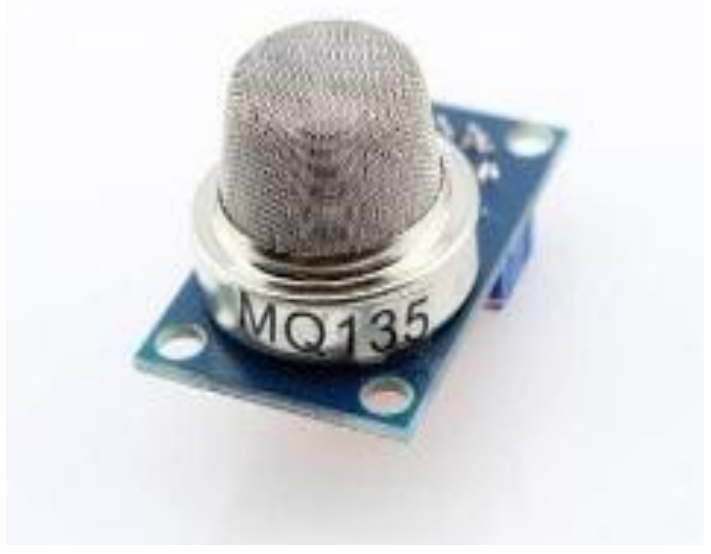

Figure 3: MQ-135 Gas sensors

\subsection{Sensitivity Characteristics MQ-135}

According to Sensitivity Characteristics (MQ-135) figure 4 the resistance ratio RS/R0. Resistances RLcan be identified is the resistance sensor changes according to gas concentration, \&
(RO) resistance sensor presence concentration of known in fresh air [8].

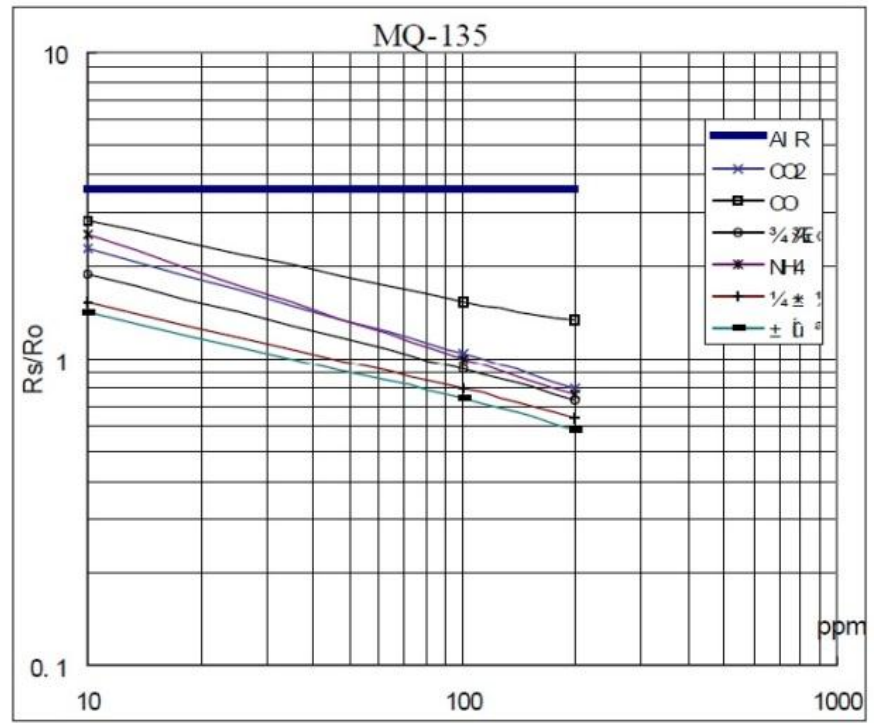

Figure 4: Sensitivity Characteristics MQ-135

1. Graph scale is log_log in a linear scale. Concentration of gas behavior as relative to the exponential resistance.

2. Concentration of gas data_range only between (10 ppm to $200 \mathrm{ppm}$ ).

3. The relationship between the ratio of resistance and the concentration of gas seems linear

\subsection{Derive a formula to find $\mathrm{RS}$}

From the electrecal circuit shows in figure 5, RS is resistor between (pin A and pin B) and resistor RL [9] where :

- (H)Pins : Out of the two H pins, one pin is connected to supply and the other to ground.

- (A)Pins : pins (A and B ) are interchangeable.They connected to the Supply voltage.

- (B)Pins : pins (A and B ) are interchangeable. One of them will serve as the output while the other will be pulled to the ground.

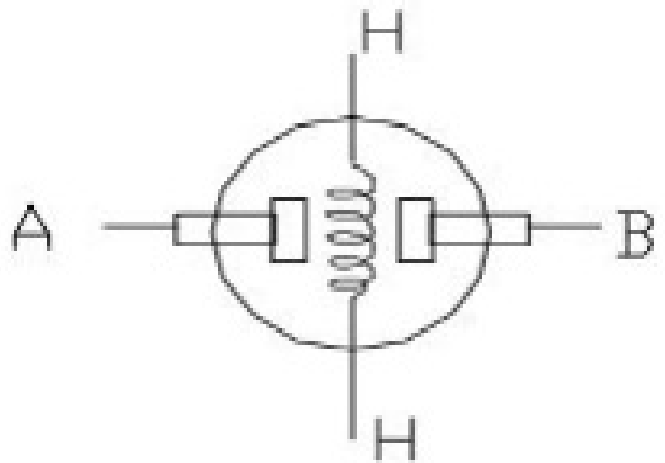

Figure 5: Sensor circuit 
By simplify circuit as shown in figure 6 .

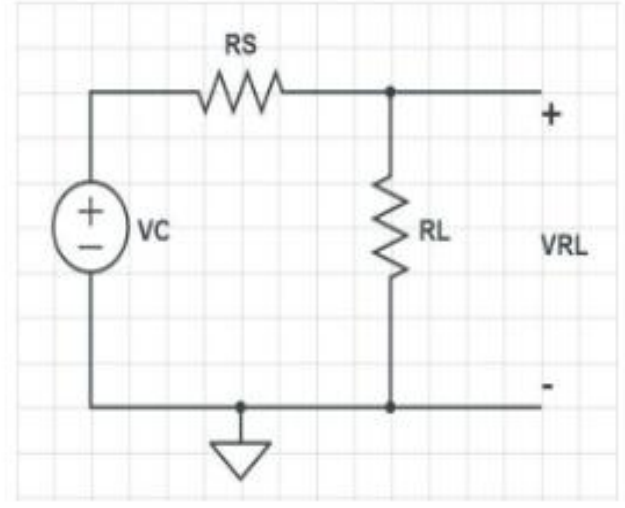

Figure 6: Circuit Simplified

Combine resistors $\mathrm{RS}$ and $\mathrm{RL}$ in series as shows in figure 7.

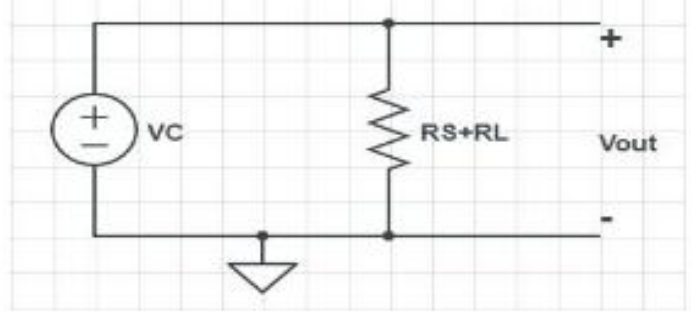

Figure 7: Combined RS and RL

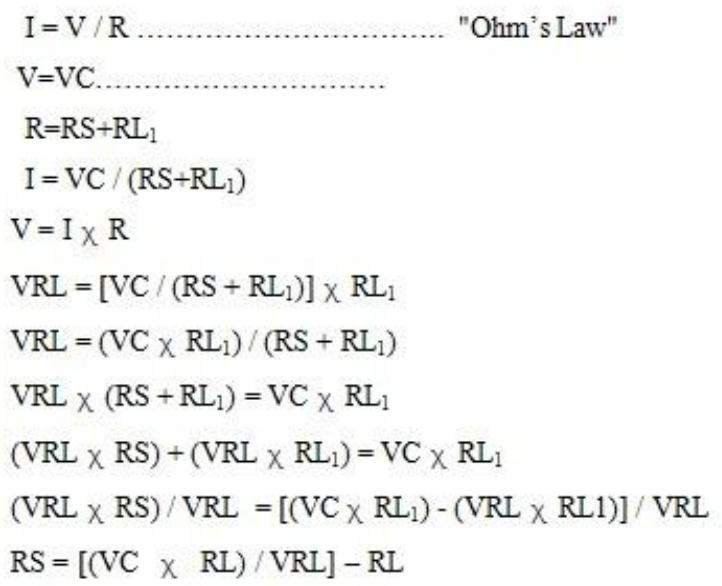

This formula (RS) used for different gases [8].

\section{SIM900 GSM GPRS Shield}

The Shield GSM GPRS Figure 8 is particularly useful because it allows compatibility with Arduino and copies, can send short text messages SMS, MMS multi-media messages, radio and GPRS by using AT commands in real-time clock[10].

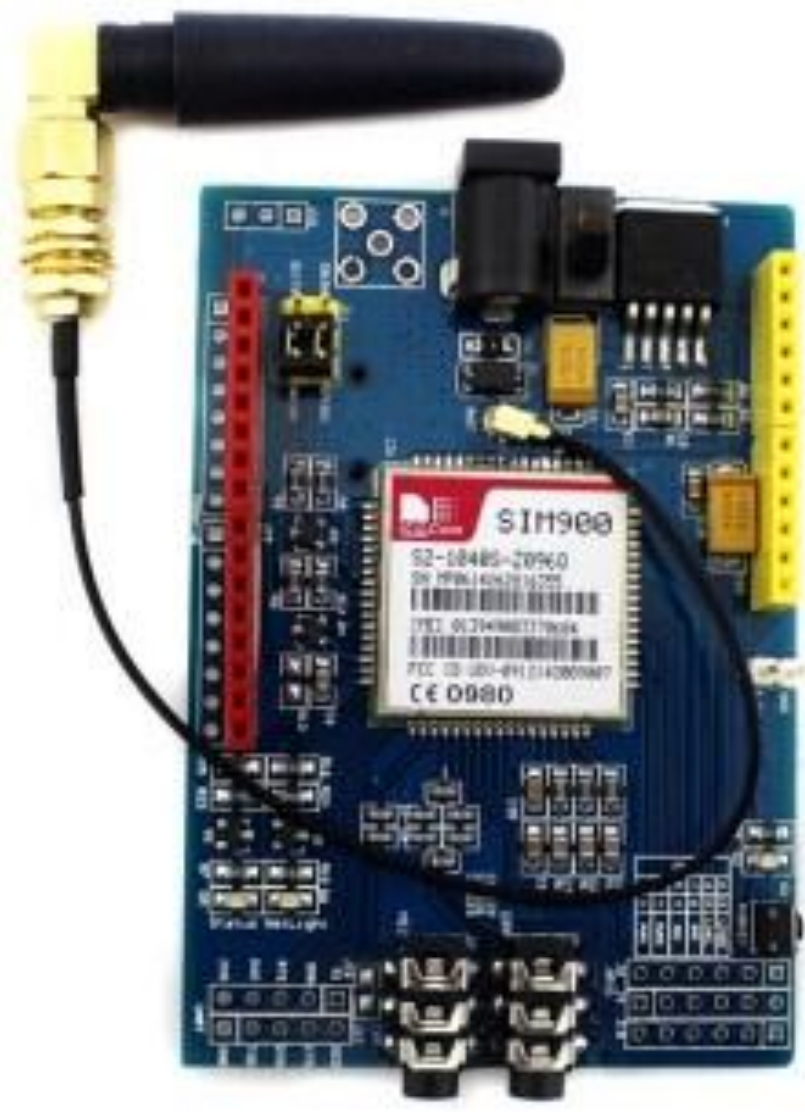

Figure 8: SIM900 GSM GPRS Shield

The shield connect to the Arduino as shows in the figure $9 \& 10$

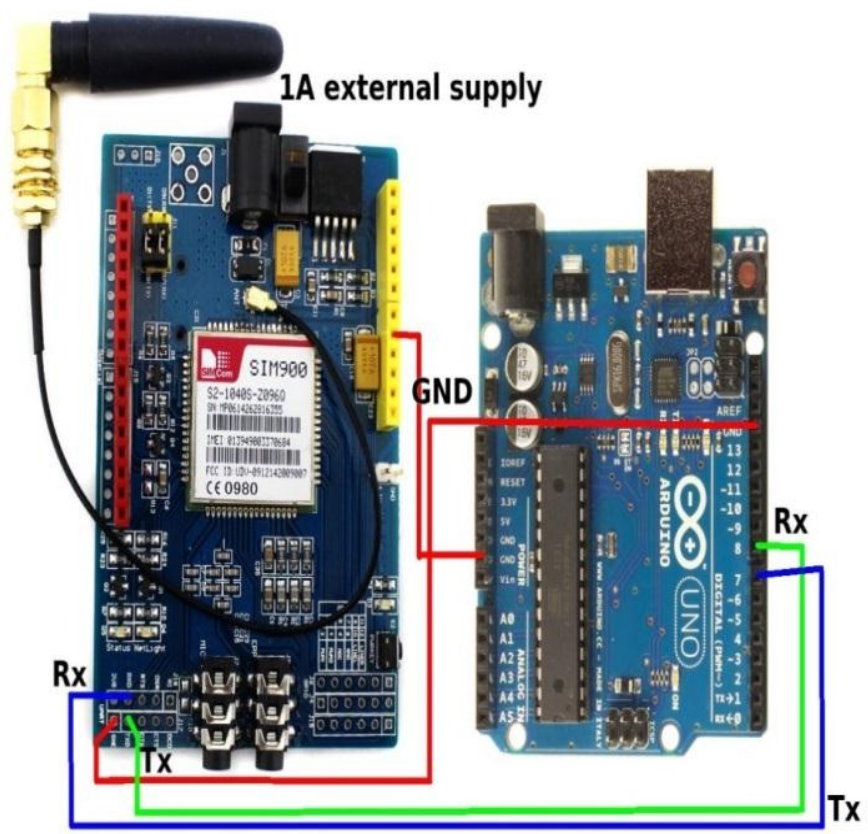

Figure 9: SIM900 shield Connection with Arduino 
International Journal of Engineering Research and Technology. ISSN 0974-3154, Volume 13, Number 10 (2020), pp. 2955-2959

(C) International Research Publication House. https://dx.doi.org/10.37624/IJERT/13.10.2020.2955-2959

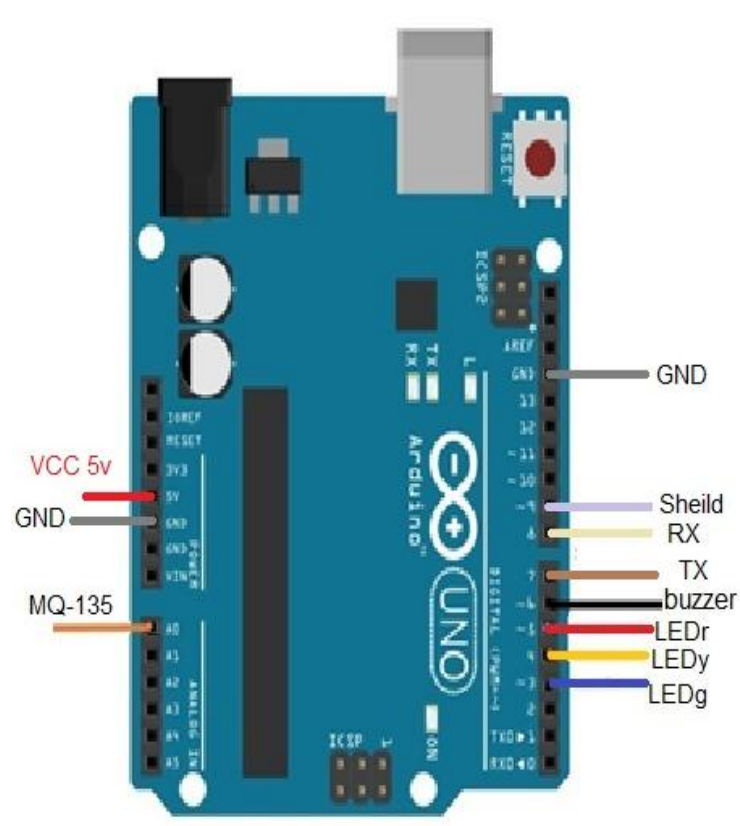

Figure 10: Arduino UNO

\section{Main coding}

๑ sketch_oct01a|Arduino 1.8 .2

File Edit Sketch Tools Help

$\checkmark \rightarrow \mathbb{0} \pm$
sketch_oct01a $\$$

\#include <SoftwareSerial.h>

\#include "Mo135.h"

SoftwareSerial mySerial $(7,8)$;//TX, RX

int air_quality;

int $\mathrm{x}$;

const int sensorPin $=0$;

int LEDr=3;

int LEDY $=4$;

int $\mathrm{LEDg}=5$;

int buzzer $=6$;

int $\mathrm{ShB}=9$;

void setup ()

f

myserial.begin (9600);

Serial.begin (9600);

digitalWrite (ShB, HIGH) ;

delay (1000) ;

digitalWrite (ShB, LOW) ;

$\operatorname{delay}(5000)$;

pinMode (buzzer, OUTPUT) ;

pinMode (sensorPin, INPUT);

pinMode (LEDr, OUTPUT);

pinMode (LEDY, OUTPUT) ;

pinMode (LEDg, OUTPUT) ;

delay (100); void loop ()

\{

MQ135 gassensor $=$ MQ135 $(\mathrm{A0})$;

delay (15000);

float air quality = gassensor.getPPM()

air_quality=air_quality ${ }^{\star} 100$;

digitalWrite (LEDg, HIGH) ;

digitalWrite (LEDY, HIGH) ;

digitalWrite (LEDr, HIGH) ;

delay (1600);

digitalWrite (LEDg, LOW) ;

digitalWrite (LEDY, LOW) ;

digitalWrite (LEDr, LOW) ;

notone (buzzer);

$\mathrm{x}=0$;

if (air_quality $<=1000$ )

\{ digitalwrite (LEDg, HIGH) ;

$\mathrm{x}=1$;

SendMessage ()

delay (10000);

\}

else if(air_quality $<2000 \& \&$ air_quality $>1000$ )

\{ digitalWrite (LEDY, HIGH);

tone (buzzer, 300);

$\mathrm{x}=2$;

SendMessage ();

delay $(1000) ;$

else if (air_quality $>=2000$ )

$\{$ digitalWrite (LEDr, HIGH);

tone (buzzer, 500);

$\mathrm{x}=3$;

SendMessage ();

$\operatorname{delay}(10000)$;

void SendMessage() \{

mySerial.println ("AT+CSCS=〈"UCS2 \"\n"); //Set the GSM in Unicode format mySerial.println ("AT+CMGF=1\r"); //Sets the GSM Module in Text Mode delay (1000);

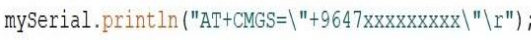

delay (1000);

Switch $(\mathrm{x})$ !

case 1 :

mySerial.println ("SMS 》 (air_quality<=1000PPM) Eresh Air");

break;

case 2 :

mySerial.println ("SMS 》(air_quality<2000PPM \&\& air_quality>1000PPM) Poor Air"); break;

case 3:

mySerial.println ("SMS 》(air quality〉=2000PPM) Danger! Move to Fresh Air") ;

break;

$\operatorname{delay}(1000)$;

mySerial.println ((char)26);

delay (1000); 


\section{Results}

After connected the hardware parts of our project as show in figure 8 and test the software we got monitoring of air pollution.

When Sensor gas MQ135 detect air quality between (1000PPM -2000PPM) the admin will got SMS message "SMS >> (air_quality < 2000PPM \&\& air_quality>1000PPM) Poor Air".

And when Sensor gas MQ135 detect air quality more than $(2000$ PPM) the admin will got SMS message "SMS >> (air_quality >=2000PPM ) Danger! Move to Fresh Air".

\section{Conclusion}

The project depends on data from gas sensors and mobile connectivity. MQ-135 gas sensor provide the system with data which is calculated to find the concentration of gases like $\mathrm{CO}$, $\mathrm{CO} 2, \mathrm{NH} 4$, Acetone, Toulene and Ethanol. Accounts are completed using Arduino program.. The final output is send massage to admin via SIM 900 and used LED \& Buzzer alarm in case there is pollutant in the indoor environment.

\section{References}

[1] http://www.arduino.cc/.

[2] http://www.arduino.org/

[3] Intisar M. Saadoon, journal of engineering and applied science, "Electroencephalography (EEG) for control the luminaire system with Arduino", Volume 14 Issue 20 (2019) Page 7448 - 7452 .

[4] Intisar M. Saadoon, International journal of civil engineering and technology, "Programming servo motors of robot arm to control directions via wii nunchuk joystick" , Volume 9 Issue 11 (2018) ISSN Online: $0976-6316$.

[5] http://www.instructables.com/.

[6] http://en.wikipedia.org/.

[5] Real Time Sticky Bomb Detection System Based on Compass Device and Arduino Board/ Sameer Hameed Majeed Computer Technology Eng. Dep. Al-Mansour University College Baghdad, Iraq/ Iraq J. Electrical and Electronic Engineering Vol.13No.1. 2017.

[7] Alternative MQ Gas sensors / HANWEI ELETRONICS CO.,LTD/ TECHNICAL DATA/ http://www.hwsensor.com.

[8] Sensors for Air Monitoring/ Rishi Kant and Shantanu Bhattacharya / Microsystems Fabrication Laboratory, Mechanical Engineering Department,Indian Institute of Technology Kanpur, Kanpur 208016, Uttar Pradesh, India doi.j/7751-7_Oct 2016.

[9] Dipanjan Bhattacharjee Electronice \& Communication Sikkim Manipal institute of Technology Sikkim manipal University, India /Environment Sensing and Energy Efficient Smart Sensor Switching /International Journal of Computer Applications (0975 - 8887) Volume 50No.23, July 2012.

[10] http://letsmakerobots.com/. 